\title{
Representation of key concepts in Belarusian and Chinese linguo-cultures
}

\author{
Inna Ilyicheva ${ }^{1}$, Chunxia Chen $^{2}$, and Anzhela Saidzi ${ }^{3}$ \\ ${ }^{1}$ Brest State A.S. Pushkin University, Republic of Belarus, ilitcheva@ list.ru ORCID 0000-0003-3610-8147 \\ ${ }^{2}$ Brest State A.S. Pushkin University, Republic of Belarus, chenxianshengde@gmail.com ORCID:0000-0002-1218-4156 \\ ${ }^{3}$ Brest State A.S. Pushkin University, Republic of Belarus, angelasaidi21 @ gmail.com ORCID:0000-0002-1818-048X
}

\begin{abstract}
The paper unfolds the content of the concepts "Bison" and "Dragon" in the Belarusian and Chinese linguo-cultures. Through reference to the study of the national language and literature in close connection with the cultures and mentalities as well as with the national identity of both countries the concepts are reconstructed through the prism of such modern linguistic disciplines as linguoculturology and linguoconceptology. The study of the means of verbal and non-verbal expressions of the concepts "Bison" and "Dragon" enables the authors to distinguish the most significant features of the concepts and point out their cultural value from the viewpoints of two contradictory trends of modernity: the processes of globalization and the desire to preserve national identity. Considering the concepts of "Bison" and "Dragon" in the Belarusian and Chinese linguo-cultures, literature, arts, heraldry, the results of the associative experiments are presented. The analysis of poetic and prose works proved the cultural value of the concepts under consideration.
\end{abstract}

\section{Introduction}

The shift of the research vector towards anthropocentrism has led to the emergence of a significant number of related integrative sciences such as sociolinguistics, ethnolinguistics, linguoculturology, linguoconceptology. And a person with his own linguistic, mental, behavioral characteristics, his own picture of the world, including individual and national awareness, has become the object of research for these sciences.

According to Russian linguoculturologist $\mathrm{V}$. Krasnykh, the starting point for the study is a person, but "not only as a carrier of a certain consciousness that performs a certain activity, but as a carrier of a linguistic consciousness that performs speech activity among other types of activities" [1].

In the process of life activity, a person organizes and categorizes his knowledge about the surrounding world by means of cognitive models which comprise mental facts and certain structures. There is an internal or mental lexicon in a person's mind, in which the central role is assigned to the word as a unit of storing the knowledge not only about a particular object, phenomenon or process, but also the knowledge about how this unit can be viewed in the language system, where it is connected by a thousand threads with other units of the same system and where it represents a concept and a special category, and even special concepts and special categories [2].

\section{Findings}

The system of concepts forms a picture of the world, which reflects a person's understanding of reality. A person lives not so much in the world of objects and things as in the world of concepts created by him for his intellectual, spiritual and social needs. Human activities for categorization and conceptualization are always linguistic in nature. E. Kubryakova rightly admits that "without being embodied in linguistic units, linguistic forms and combinations of these units and their forms in discourse, neither this activity itself, nor summing up its results, simply could not exist" [3].

In her works V. Maslova repeatedly points out that from the standpoint of cognitive linguistics, the concept should be considered within the framework of the language-culture dyad. In this tradition, the concept is defined, according to V. Maslova, as being localized in the mind, but at the same time its national and cultural originality is in the centre of attention [4].

V. Telia considers the "concept" as "everything that we know about the object in the entire extension of this knowledge" [5]. The concept is a significant category of the highest degree of abstraction, which includes individual meanings of concretizing general semantics. The modern world is dismembered by man and is represented in different languages in different ways precisely because in each natural language it appeared exclusively in the form of the results of the processes of categorization and conceptualization of the world that proceeded differently in the respective languages [6]. 
The mentality of the people, as V. Maslova sees it, is the world perceived by a person through the prism of his native language, in its basic forms and categories as well. Mentality forms the linguistic consciousness of the people [7]. Language is the most important means of formation and existence of human knowledge about the world. Reflecting the objective world in the process of his activity, a person fixes the results of cognition in the word. Awareness of the concept as a mental unit allows not only to reconstruct the mental world of a speaker of a certain language, but also to recreate his ethnocultural image of the world, for, developing the thesis of Yu. Stepanov [8], concepts can be presented as a fundamental unit of culture in a person's mental world.

The article focuses on various ways of manifestation of the key concepts "Bison" and "Dragon" in the Belarusian and Chinese linguo-cultures. As the basic material for the study the authors chose the primary element of the Belarusian and Chinese cultures the corpus of poetic texts. Each national culture is distinguished by poetic texts reflecting a special culture code (images, symbols). Precisely this type of textual material actualizes the body of knowledge and ideas characteristic of the consciousness of a collective linguistic persona.

The basis for the research is made of the corpus of randomly chosen examples from explanatory, etymological, phraseological and paremiological dictionaries of the Chinese and Russian languages (10 dictionaries); 80 poetic and 10 prose works by regional authors.

Research methods include cognitive-discursive modeling of concept meanings in various contexts; a descriptive method based on direct observation of linguistic material; method of linguoculturological commenting.

A cultural concept is a multidimensional mental phenomenon, in which researchers (N. Boldyrev, S. Vorkachev, V. Karasik, V. Stepanov) distinguish several qualitatively different components (layers, measurements, etc.). The associative component of the concept occupies a special place in the multilayered structure. The associative component is investigated by analyzing the associations caused by the stimulus - the name of the concept.

For the research purposes, two associative experiments were carried out, in which Belarusian and Chinese students aged 20 to 28 took part (in each group 30 people). During the experiment, we used the technique of a written survey in Russian and Chinese, respectively.

In the course of the chain associative experiment, the students were asked to name the "national animal" and respond to the word with any verbal reaction. As a result of the experiment, 251 reactions were obtained. In this case, multiple free associations were used: the students were asked to write down the first 5 reactions that came to their minds (words of any part of speech) to a stimulus word. Paradigmatic reactions (synonyms, hyperonyms, antonyms), syntagmatic reactions (attributive words adjectives, participles, genitive nouns), word combinations (stable and free) were taken into account.
The results of the associative experiment demonstrate the following data: $97 \%$ of Belarusian students identified the bison as a national animal, $98 \%$ of Chinese students identified the dragon as a national animal. At the stage of interpretation and statistical processing of associative reactions, the signs of the associative field of the concept "Bison" and "Dragon" were established, which made it possible to make an attempt to reconstruct it.

For the linguistic consciousness of the Belarusian students, the word "Bison" evokes, first of all, the following associative reactions: a symbol of greatness (30); large animal (30); an ancient animal (27) a dangerous animal (21), an animal covered with thick wool (15).

The nuclear reactions to the "Dragon" concept in the Chinese linguistic consciousness are as follows: the dragon is associated with the origin of the Chinese people (30), the symbol of the emperor (29), the symbol of happiness (27), the symbol of miraclulous life (23), the symbol of the top spiritual power (19).

To clarify the basic meaning of the concepts "Bison" and "Dragon", the authors refer to lexicographic sources. The lexical meaning of the concept "Bison", recorded in the Russian-language explanatory and etymological dictionaries (S. Ozhegov, S. Kuznetsov, G. Krylov, M. Fasmer) is as follows: bison. common slav. suf. derivative (suff. -r-) from a tooth <* zǫbъ in the meaning of "horn, fang". Bison literally means "horned" (beast). A wild bull that looks like a bison.

For the lexicographic designation of the concept "Dragon" in the Chinese language since ancient times there has been a separate hieroglyph - 龙. The famous Chinese scholar Xu Shen, who lived in the 1-2nd centuries $\mathrm{AD}$, created the first systematized Chinese dictionary 'Showen Jiezi", in which a separate hieroglyph for the dragon was presented.

To perform the next stage of the research, the following tasks were set: 1) to describe the features of the functioning of the concepts under study in Chinese and Belarusian poetic and prose texts (the level of textual implementation of the concept); 2) to identify ways of non-verbal representation of concepts in the communicative regional space.

To study the level of textual implementation of concepts, databases were compiled containing contexts of poetic and prose works, as well as paremiological units.

The analysis shows that in the Belarusian poetic and prosaic discourses, the representation of the concept of "Bison" is predominantly verbal. The first to glorify the strength and courage of bison in literature was Belarusian educator and poet Nikolai Gusovsky. At the beginning of the 16th century, he wrote the famous "Song of the Bison", in which the bison became the main character in the poem. Many pages are devoted to the description of the bison's physique, behavior in its habitat, hunting scenes, etc. The dominant position is occupied by the description of the beauty of the bison in motion: "... gorgeous, the glory of our forests"; "the beauty of the bison is especially noticeable when it runs: you love to see how easily he runs in his impetuous 
motion And along the forest glades, and along the swamp paths. He will jerk off from its place, as if thrown up with a sling".

The analysis of the images that actualize the concept of "Bison" in the lyrics of Brest regional authors allows us to single out three more images: the lord of the forest space, a living legend, a symbol of primitive power. So, for many authors, bison is a living legend, a witness of events that have taken place over the centuries. In the lyrics of P. Brovka "bison is walking in the waves of Puscha sea". The poet characterizes bison as the lord of the forest space and describes him as the most powerful and dignified animal of the Puscha.

In a number of prosaic texts, the bison occupies the dominant position as a symbol of primal power. The proof to this approach we could find in the works of G. Kartsov, who admits that "the bison has never had a cowardly appearance; even on the run from danger, he is still rather scary"; "the bison was much larger than the American bison that I hunted or saw; its coat is thin, long and not curly; the color of the bison is of a light shade".

Unlike the bison, the image of the dragon can be found in ancient myths, where the dragon acts as the ancestor of humanity, an outstanding national sage, the first Chinese emperor. At the dawn of civilization in China, the dragon was worshiped as the main totem. The beginning of dragon worship is a direct reflection of the primal totemic cult. In the Chinese mind, a dragon is a creature endowed with positive traits. Unlike the western tradition, where the dragon is a symbol of evil and danger, in China a characteristic feature of the image of the dragon is that he does only good and behaves wisely.

According to written legends, the dragon is the totem animal of the ancestor of the Chinese nation $\mathrm{Fu} \mathrm{Xi}$, in the "Catalogue of Mountains and Seas" it is said: "The gods of deep antiquity, brother and sister Fu Xi and Nuiwa, had the body of a dragon and the face of a man". Moreover, the Chinese identify themselves as "the descendants of Yan-di and Huang-di", that is, the descendants of the first two Chinese emperors. In ancient literary monuments, it is recorded that Yan-di and Huang-di were the embodiment of a dragon, thus, the historical continuity of the Chinese nation was established.

Of numerous types the dragon found in mythological and folklore texts, four dominant images should be distinguished in Chinese folk sayings: the yellow dragon (Huanglong-黄龙), the divine dragon (Shenlong-神龙), personifying clouds and winds, the rain-sender, Green dragon (Qinglong - 青龙), meaning a lucky omen and a water dragon (Jiaolong- 蛟龙) that causes floods. In the classic "Book of Changes", the dragon stands for the sage. The great Confucius called the great Chinese thinker Lao Tzu "dragon".

The appearance of the Chinese dragon is rather heterogeneous, and with the change of different historical periods, it has also undergone many changes. By the time of the Ming Dynasty, the image of the dragon was gradually fixed and the foundation of today's dragon appearance was laid. The famous Chinese physician Li Shizhen wrote in his book "Compendium of Medicinal Substances": "The dragon is the lord of all animals. Once the philosopher Wang Fu, describing the type of dragon, drew analogies with nine animals: the head of a dragon resembles a camel, horns - a deer, eyes - a hare, ears - a bull, neck - a snake, belly - a toad, scales - a carp, claws - a kite, paws - tiger"（头 似驼, 角似鹿, 眼似兔, 耳似牛, 项似蛇 , 腹似蜃, 鳞似鲤, 爪似鹰, 掌似虎, 是 也。).

In the works of Chinese literature, there are many descriptions of the dragon. For example, in the book "Showen Jiezi" ("Explanation of Simple and Interpretation of Complex Signs") by a Chinese philologist during the Eastern Han dynasty it is written: "The dragon is the sovereign of all animals, it can hide in secret places, it can appear in an open place. It can become small or huge, short or long. During the vernal equinox it can soar in the sky, during the autumn equinox it can plunge into the depths of water". (龙, 鳞虫之长。能幽能明, 能细能巨, 能短能长。春分而 登天,秋分而潜渊)

The poet of Jin Wanyan Liang era wrote the verse "Ode to the Dragon", where the following lines are found: "When the dragon lurks in the sea waters, it mixes with ordinary fish and shrimps, but as soon as it shows itself, it can shake the earth, and the mountains and rivers will change color” (蛟龙潜医隐苍波， 且与虾蟆作混和。等待一朝头角就, 撼摇霹 雾 震 山河).

The generalized image of the dragon is actively used in the paremiological fund of the Chinese language, creating a special zoomorphic code. Phraseologisms with the name of the dragon are distinguished by a high degree of prevalence and universality, they are actively used in speech activity as a figurative characteristic of a person, situation, event, have a high evaluative potential: examples 人中之龙 (Dragon in a man), 望子成龙 (Parents want their children to be as successful as a dragon).

The bison and the dragon are important companions of man, and their images in painting and sculpture demonstrate the worship of these animals. In its most general meaning, bison is a symbol of grandeur, monumentality and royalty. Masterpieces in Belarusian art demonstrate all these symbolic features of the animal, and also show "qualities in motion" along with grace and harmony of proportions. In a number of Belarusian landscape sketches, the concept of "Bison" is masterfully embodied.

The concept "Bison" is quite stable in regional sculpture. In the city of Kamenets, Brest region, near the Kamenets tower, in 1988, a monument was erected to its founder - the great Volyn prince Vladimir Vasilkovich. The monument has a rather original compositional solution: the majestic figure of the city founder, prince Vladimir Vasilkovich, is shown in full growth. Next to him, there is a royal bison - the symbol of Belovezhskaya Pushcha, in the immediate vicinity of which the city of Kamenets is located. A sculpture of a 
bison made of wooden beams is erected at the National Airport of Minsk. The silhouette of a bison is present on the emblems of sports championships and clubs, commemorative coins, logos of food products, the chevron of the uniform of forestry employees.

The dragon is also the most powerful symbol of Chinese art. This mythical character is presented in most of the plaster bas-reliefs, ornaments and sculptures in China. In Chinese culture, the dragon is the lord of all animals, he is at the top of the food chain, he is the personification of two leaders of the clan - Yan-di and Huang-di. In Chinese politics, he is also given special significance. Since the times of the ancestor of the Chinese nation, Emperor Huang Di, the dragon has become a symbol of power, Chinese emperors from many dynasties called themselves "sons of heaven" （天 子), as well as "real dragons" (真 龙). Since then the dragon has become a symbol of imperial power. "Dragon chair" (龙椅) is a phrase that denotes the throne of the reigning emperor in the imperial court with an engraved image of a dragon on which he receives ministers and dignitaries, it symbolized the highest imperial power. "Gown with a dragon" (龙袍) is the dress of the emperor, "the body (health) of the dragon"

(龙 一) is the health of the dragon, "the sons and grandsons of the dragon”（龙子龙孙） are the sons, grandsons of the emperor and subsequent generations.

Stucco bas-reliefs depicting nine dragons can be found everywhere in China. However, the most famous example is the famous "Wall of the Nine Dragons" in Beijing. Moreover, each mythical character has its own characteristics, name and performs certain functions: 1) $\mathrm{Pu}$-lao (蒲 牢) warns of danger and serves as a protector. The dragon Pu-lao is often engraved on bells, sacred bowls and gongs; 2) Qiu-nu (囚 牛) is Yang energy creator. This character wields his power through the use of ancient Chinese music; 3) Pee-hises (狴 犴 ) is considered the owner of knowledge and virtue. His image is especially often used in the design of educational institutions; 4) Pa-xia (霸 下) is the main provider of strength and support that the Chinese turn to in times of need. It is often used when decorating temples; 5) Chao-feng (嘲 风) is the keeper of the holy places, he protects the peace of the sacred lands and holy temples; 6) Chao-wen (螭 吻) symbolizes the power of water over fire; 7) Suan-ni (狻猊) is a powerful defender and amulet against any negative intentions - theft, loss or betrayal; 8) Yai-tzu (睚眦) protects people from all types of injury and physical harm; 9) Pi-Kau (貔㤥休) is the patron saint of fair trials and oral disputes. It is believed that the image of Pi-Kau protects people from slander, gossip, and false accusations.

In China, there is a tradition of decorating various objects with dragon images, for example, a cane with a dragon's head, as well as a stringed musical instrument with a dragon's head. The tradition originated more than a thousand years ago, and it is still followed by the present generation. Moreover, dragon images can be extensively found is interior and exterior decorations.
In China, the Duan-Wu holiday is held annually, during which, according to tradition, "dragon boat races" are organized. These boats outwardly resemble a dragon, they are called Long Chuan or Long Zhou - 龙舟 (translated from Chinese as a dragon and a boat). This holiday is celebrated throughout the country, it is believed that this holiday is associated with the memory of the great poet $\mathrm{Qu}$ Yuan who was a thinker of the Chu principality (475-221 BC). The residents of the Chu principality, having learned about his death in the Milojiang River, went to sea in boats to rescue him. Also, the Chinese celebrate the holiday of spring and lanterns (the 15th of the first lunar month). During this festival dragons can be seen dancing merrily. The dragon dance is popularly called Wu Long (舞龙). To achieve a special effect the designers stick some glowing substance into the bodies of the dragons and in the dark they look fascinating.

Images of a bison and a dragon are present in national and regional heraldry. Unlike a speech utterance, which is built from words, a work of fine art, in this case heraldry, is an integral, complete, creolized unit. The semantics of color and iconic signs become symbolic and nationally significant for the native speakers of the language and the culture of a particular region. The coat of arms of the National Park "Belovezhskaya Pushcha" includes a number of components, each of which performs a corresponding function. The core is a shield with a coat of arms. The coat of arms has a crown, above the crown there is an oak tree brunch, the base and roots are also oak base ans roots of which rest against the foot, which is presented in the form of a grass bedding. The shield holders on both sides of the coat of arms are depicted in the form of two large animals living in Belovezhskaya Pushcha - a red deer and a bison.

\section{Conclusions}

In Chinese palace heraldry, only the emperor had the image of a dragon with five claws, while the courtiers wore the emblems of dragons with three and four claws. The image of a dragon with five claws was interpreted as the power of the emperor, dominating the four forces of nature.

The study of the national language and literature in close connection with the culture and mentality, the national identity of each people inevitably draws researchers to the concept studies, the reconstruction of which is one of the priorities of such modern linguistic disciplines as linguoculturology and linguoconceptology.

The study of the means of linguistic expression, as well as the reconstruction of the most significant concepts are important for understanding the specific features of each national culture and for the successful interaction of cultures, which is relevant now, given the two contradictory trends of modernity: the processes of globalization and the desire to preserve national identity.

Having considered the concepts of "Bison" and "Dragon" in the Belarusian and Chinese linguo-cultures and the characteristics forming them, we have come to 
the conclusion that the conceptual field of the concepts under study is quite extensive. The results of the associative experiment and the analysis of poetic and prose works have proved the cultural value of the concepts under consideration. The concepts "Bison" and "Dragon" are an important part of the human mentality both in Belarus and in China, as a cultural and linguistic unit, they are expressed in various languages, reflect the peculiarities of the culture of the people.

\section{References}

1. V.V. Krasnych, Questions of psycholinguistics E 7, 53 (2008)

2. E.S. Kubryakova Language and knowledge: On the way of acquiring knowledge about language: Parts of speech from a cognitive point of view. The role of language in the knowledge of the world, 306 (2004)

3. E.S. Kubryakova In search of the essence of language: Cognitive research, 37 (2012)
4. V.A. Maslova Introduction to cognitive linguistics: textbook. Allowance, 61 (2011)

5. V.N. Telia Russian phraseology. Semantic, pragmatic and linguoculturological aspects, 97 (1996)

6. E.S. Kubryakova In search of the essence of language: Cognitive research, 38 (2012)

7. V.A. Maslova Conceptual foundations of modern linguistics: textbook. Allowance, 47 (2019)

8. Yu.S. Stepanov Constants: a dictionary of Russian culture, 5 (2004)

9. 何星亮. 中国龙文化的发展阶段 $[J]$. 云南社会科学, 1999(06):57-64.

10. 间世斌.从龙文化看民族精神 $[J]$. 学术交流,2006(02 )$: 30-34$.

11. 张鹤,张玉清. 中国龙文化的形成发展和中外文化交 流 $[J]$. 河北师范大学学报 (哲学社会科学版),2008 (02):157-160.

12. 庞进. 龙文化的历史职能、精神底蕴和重要使命 $[J]$. 商洛学院学报, 2010, 24(01):3-8. 